\title{
AplicaCión del ARTículo 146 DEL Código ORgáNICO DE TRIBUNALES AL JUICIO DE INCONCURRENCIA. SENTENCIAS DE LA CORTE SUPREMA DE 2 DE DICIEMBRE DE 2013
}

\section{RUgGero CoZZI Elzo*}

\section{1) LOS HECHOS}

El juicio ejecutivo de inconcurrencia, regulado en los artículos 196 y siguientes del Código de Minería ("CdM") es un procedimiento ejecutivo especial, propio de las sociedades legales mineras ("SLM"). Permite a la SLM perseguir el pago de la cuota para contribuir a los gastos sociales de conservación y explotación de la concesión minera, pudiendo embargar y rematar las acciones que correspondan al socio inconcurrente ${ }^{1}$. En la jurisprudencia que se comenta, los hechos fueron los siguientes:

- Varias SLM son dueñas de diferentes pertenencias de litio ubicadas en la comuna de Copiapó e inscritas en el Conservador de Bienes Raíces de la misma comuna;

- Las SLM han fijado convencionalmente su domicilio social en Santiago. En esa ciudad, entonces, se celebran las juntas de accionistas que fijan la cuota para contribuir a los gastos sociales de cada SLM;

- Producida la mora de varios socios, y sirviendo como título ejecutivo la copia del acta de las juntas de accionistas, cada SLM demanda a los socios inconcurrentes en juicio ejecutivo, embargándose las acciones de cada socio moroso. Las demandas se deducen en los juzgados civiles de Copiapó, invocando el artículo 146 del Código Orgánico de Tribunales ("COT"), el cual dispone: "Conocerá de todos los asuntos a que se refiere el Código de Minas, el juez letrado que tenga jurisdicción en la comuna o agrupación de comunas en que esté ubicada la pertenencia. Lo cual se entiende sin perjuicio de las disposiciones especiales que se establecen en el mismo Código de Minas, en este Código y en el de Procedimiento Civil'.

- Los ejecutados oponen excepción de incompetencia fundada en que la materia del juicio dice relación exclusivamente con la administración de la sociedad, siendo el tribunal del domicilio social el competente según las reglas generales (art. 134 y 138 del COT). Según los

Abogado. Licenciado en Derecho, Pontificia Universidad Católica de Chile (CHILE). Correo electrónico: rceabogado@gmail.com

1 Lira Ovalle, Samuel (2012) Curso de Derecho de Minería. Santiago: Editorial Jurídica de Chile. $6^{a}$ Ed. pp. 217 y ss. 
arts. 183, 189 y 195 del CdM, entre otros, el domicilio de la SLM es el factor determinante de competencia para las controversias de la administración, y lo mismo debiese aplicarse, por analogía, al juicio de inconcurrencia.

\section{2) Problemas de interpretación. Aplicación del artículo 146 DEL COT AL JUICIO DE INCONCURRENCIA}

En un sentido restringido, el juez debe interpretar solamente frente a pasajes vagos o ambiguos: si el texto es claro, no se debe interpretar (in claris non fit interpretatio). En un sentido amplio, por el contrario, si se considera que el derecho se manifiesta a través del lenguaje, la interpretación es siempre un presupuesto necesario para la aplicación del derecho en la medida que se le atribuye significado a un enunciado ${ }^{2}$.

Siguiendo a Ricardo Guastini ${ }^{3}$, un primer grupo de problemas de interpretación nacen de la vaguedad o ambigüedad de los textos sujetos a interpretación. La vaguedad es una propiedad de la referencia de los predicados: un predicado es vago siempre que la pregunta "¿a qué cosa se refiere?” resulta dudosa. En cambio, la ambigüedad puede ser semántica (por la pluralidad de significados de una palabra); puede radicar en la sintaxis del enunciado (debido a su estructura lógica); o bien, provenir del contexto de la expresión que se interpreta (por las diversas funciones del lenguaje). La vaguedad y ambigüedad del texto se solucionan mediante un ejercicio interpretativo: la vaguedad, determinando la referencia del predicado; la ambigüedad, decidiendo entre dos o más significados en competencia.

Un segundo grupo de problemas de interpretación son las denominadas antinomias. Estas suceden cuando, frente a un mismo supuesto de hecho, existen dos reglas aplicables que entran en conflicto. La incompatibilidad que producen las antinomias se supera mediante la no aplicación de alguna de las normas en oposición, ya sea por abrogación, ya sea por invalidez. La inaplicabilidad de alguna de las normas en conflicto puede decidirse por las reglas de especialidad (lex specialis), temporalidad (lex posterior), y jerarquía (lex superior).

Un tercer grupo de problemas son los vacíos normativos o lagunas. Esto es, cuando frente a un supuesto de hecho no existe regla aplicable para darle solución. El principio de inexcusabilidad le exige al juez re-

\footnotetext{
2 Ursúa, José Francisco (2004) “Interpretación jurídica: una propuesta de esquematización de planteamientos". Isonomía. Revista de Teoría y Filosofía del Derecho, N²0, abril 2004. p. 256.

3 Guastini, Ricardo (1993) "Problemas de interpretación”, Le fonti del diritto $e$ l'interpretazione (Milán, 1993), cap. XXV, trad. cast. de Miguel Carbonell (IIJ-UNAM), en Isonomía. Revista de Teoría y Filosofía del Derecho, N 7, octubre 1997. pp. 121-131.
} 
solver la controversia, aun a falta de ley, integrando el ordenamiento. Para ello puede acudirse a la analogía (argumento a simile) o la diferencia (argumento a contrario). Mediante la analogía se construye una norma que tenga consecuencia idéntica a la de otra u otras con un supuesto afín; en cambio, mediante la diferencia se integra el ordenamiento jurídico construyendo una norma que tenga consecuencia opuesta (contraria) a la de otras con un supuesto semejante ${ }^{4}$. Cuando no es posible acudir a la analogía o diferencia, el vacío puede ser integrado mediante la creación del juez, quien ańade una norma a partir de los principios generales del derecho o desde la equidad 5 .

El artículo 146 del COT regula "todos los asuntos del Código de Minas". Es, entonces, una regla de competencia absoluta en razón de la materia, atendida la relación jurídica donde surge el conflicto que es sometido al conocimiento del tribunal ${ }^{6}$. En la determinación de la jerarquía del juez competente para conocer de los asuntos mineros, la aplicación del 146 del COT cede frente al factor fuero, pero es preferente a la cuantía. Sobre la competencia relativa, el artículo 146 del COT especialmente se ha encargado de conectar los asuntos mineros con un territorio determinado: será competente aquel juez letrado de la comuna o agrupación de comunas "en que esté ubicada la pertenencia".

En 1943, el Código Orgánico de Tribunales estableció el actual artículo 146, sin que haya sido modificado mayormente a la fecha ${ }^{7}$. Sin embargo, con posterioridad, en 1983, fue dictado el actual Código de Minería que establece varias reglas de competencia para diversos asuntos mineros. No obstante, el solo criterio de lex posterior no es suficiente para solucionar los conflictos entre las reglas de competencia minera del CdM y el artículo 146 del COT. Necesariamente habrá que acudir al principio de lex specialis.

De acuerdo a un criterio cuantitativo, una ley es especial cuando se aplica expresamente a un menor número de casos que aquel a que se aplique expresamente la norma contraria, la cual se considerará entonces, ley general ${ }^{8}$. Entonces, las distinciones general-especial son siempre relativas:

4 Guasp, Jaime (1968) Derecho Procesal Civil. Madrid: Instituto de Estudios Políticos. p. 65.

5 Ugarte Godoy, José Joaquín (1982) "La integración de la ley con la equidad y la retrocesión", Revista de Derecho y Jurisprudencia y Gaceta de los Tribunales, № 1 Tomo 79. Publicado en Doctrinas Esenciales (2010) Santiago: Puntolex.

6 Sobre la materia como factor determinante de la competencia absoluta, ver: Romero SEguel, Alejandro (2009) Curso de Derecho Procesal Civil. Los presupuestos procesales relativos al órgano jurisdiccional. Santiago: Editorial Jurídica de Chile. T. II. p. 51.

7 La única reforma ha sido por Ley $\mathrm{N}^{\circ} 18.776$, D.O. de 18 enero de 1989, que introdujo la división territorial de comunas y regiones.

8 Carnelutti, Francesco (1944) Sistema de Derecho Procesal Civil. Argentina: UTEHA. V. I. p. 133. En cambio, según un criterio cualitativo, una ley es especial si la norma es introducida contra tenorem rationis proper aliquam utilitatem, es decir, la norma que pugna con el espíritu del sistema. 
una regla considerada especial puede ceder frente a otra regla particular dirigida a un grupo más reducido -digamos, más especial-, y así sucesivamente. Por ello, no debiese sorprender la segunda parte del artículo 146 que contiene una regla de excepción ("sin perjuicio de las disposiciones especiales").

El artículo 146 del COT regula un conjunto de casos reducido, agrupados según su naturaleza minera. En esa lógica, el artículo 146 es especial en relación a la regla de los artículos 134 y 138 del COT; pero es general, en relación a otras disposiciones particulares de competencia que puedan existir para asuntos mineros más específicos. Por ejemplo, el artículo 231 del CdM que rige especialmente para asuntos atinentes al pedimento, manifestación, concesión de exploración o pertenencia.

En la controversia de competencia suscitada en relación al juicio ejecutivo de inconcurrencia, que nos presentan los fallos en análisis, los ejecutados han intentado construir un conflicto de normas donde no existe. En sentido amplio, se hace necesario interpretar las normas aparentemente incompatibles y resolver cualquier antinomia.

Como dijimos, el artículo 146 del COT es una regla de competencia absoluta determinada por el factor materia, aplicable a la generalidad de los asuntos mineros. Se trata de una regla especial de competencia; pero al mismo tiempo, constituye la regla general para los asuntos mineros. Ello obliga al juez a preguntarse si hay o no una regla especial de competencia para el juicio ejecutivo de inconcurrencia. Si la respuesta es negativa, se aplica la regla especial para la generalidad de los asuntos mineros (art. 146 del COT); si la respuesta es positiva, se aplicará la regla específica -más especial-sobre juicio de inconcurrencia.

Es aquí donde los ejecutados plantean una antinomia. Supuestamente, otros preceptos ofrecen una solución distinta frente al mismo supuesto de hecho: los artículos 183, 189 y 195 del CdM confieren competencia al juez del domicilio social para conocer de las controversias que surjan en la administración de las SLM. Pero la antinomia es solo aparente. Lo cierto es que ninguna de esas normas especiales asigna una competencia específica para el juicio de inconcurrencia. Las normas del CdM citadas por los ejecutados para plantear la incompatibilidad, en realidad, regulan supuestos de hecho diferentes al juicio de inconcurrencia. No hay una antinomia entre estas y la norma del 146 del COT. La excepción ínsita del artículo 146 del COT no se aplica pues no existe "disposición especial" que regule la competencia en el juicio de inconcurrencia?

9 Con el mismo argumento debe rechazarse la aplicación del artículo 231 del CdM al juicio de inconcurrencia, pues no se trata de un asunto atinente al pedimento, manifestación, concesión de exploración o pertenencia, supuesto de hecho completamente distinto y que no viene al caso. 
Un elemento interpretativo adicional es la prohibición de la analogía que existe para cierto tipo de normas. En el derecho italiano, la integración por analogía está expresamente prohibida para tres categorías de normas: las penales, las restrictivas del libre ejercicio de los derechos ${ }^{10}$ y las excepcionales. En nuestro medio, Carlos Ducci afirma que la interpretación restrictiva se aplica en el caso de las leyes penales, leyes tributarias, leyes de excepción, preceptos prohibitivos, los que establecen incapacidades y prohibiciones, las leyes delegatorias, las que confieren un beneficio, y las que limiten el derecho de propiedad, entre otras. En ninguno de estos casos sería posible recurrir a la interpretación extensiva o por analogía ${ }^{11}$.

La jurisprudencia ha entendido que las normas que fijan la competencia absoluta, siendo de orden público, son leyes de excepción que no admiten analogía. En efecto, como explica Romero Seguel, "[l]as reglas de competencia absoluta son de orden público y, por ende, son irrenunciables para el Tribunal y para las partes. En cambio, las normas de competencia relativa en materia civil contenciosa son renunciables mediante la institución de la prórroga de competencia" ${ }^{12}$. Dicha naturaleza de la competencia, pública o privada, permite zanjar varias dudas sobre su interpretación. Ya la Corte de Apelaciones de San Miguel, desechando la posibilidad de que sea la autoridad administrativa quien declare la existencia de una relación laboral, cuestión exclusiva de los tribunales de justicia, ha declarado que "en este contexto, y en el de la interpretación restrictiva que procede respecto de normas de orden público, como es que fijen la competencia para conocer de los conflictos laborales y, especialmente en presencia de los principios de legalidad y juridicidad que informan la normativa de sendos incisos primeros de los artículos 6 y 7 de la Constitución Política de la República, resulta de mediana claridad que escapa absolutamente del marco de acción de la autoridad administrativa, el dilucidar y resolver controversias de orden jurídico que se susciten entre trabajadores y empleadores"13. Los fallos de la Corte Suprema que aquí se comentan, confirman dicha doctrina.

10 En Chile encontramos una manifestación de aquel criterio en el artículo 5 inciso segundo del Código Procesal Penal, el cual dispone: "Las disposiciones de este Código que autorizan la restricción de la libertad o de otros derechos del imputado o del ejercicio de alguna de sus facultades serán interpretadas restrictivamente y no se podrán aplicar por analogia".

11 Ducci Claro, Carlos (2005) Derecho Civil. Parte General. Santiago: Editorial Jurídica de Chile. $4^{a}$ Ed. p. 94.

12 Romero Seguel, Alejandro (2009) Curso de Derecho Procesal Civil. Los presupuestos procesales relativos al órgano jurisdiccional. Santiago: Editorial Jurídica de Chile. T. II. p. 49.

13 Corte de Apelaciones de San Miguel. Rol 95-2003. 2 de junio de 2003. "Asociación Gremial Dueños Buses Autobuses Melipilla Santiago AG con Inspector Provincial del Trabajo Melipilla" (recurso de protección de garantías constitucionales) cita LegalPublishing: CL/ JUR/2751/2003. 
Eventualmente, sin embrago, podría suceder que según el artículo 146 del COT fuesen competentes en razón del territorio varios jueces, al estar involucradas en el juicio de inconcurrencia pertenencias inscritas en distintas comunas. Es lo que plantea el voto disidente de las sentencias que se comentan. Cabe preguntarse si es aplicable en esos casos la institución de la prórroga de competencia (art. 181 y ss. del COT). En sentido estricto, no procede la prórroga de competencia al no ser el juicio de inconcurrencia, ni ninguno de los asuntos regulados en el 146 del COT, una materia contenciosa civil sino un asunto contencioso minero. Pero volviendo sobre lo ya dicho, la competencia territorial es de orden privado; a diferencia de la competencia absoluta, sí podría ser interpretada extensivamente o por analogía.

Si consideramos que en el juicio de inconcurrencia la SLM deduce una acción ejecutiva mueble -para el pago de una obligación en dinerocontra uno de sus socios, cobra sentido lo dispuesto en la parte final del artículo 139 del COT. Por analogía, sería competente territorialmente cualquiera de los tribunales en que, estando ubicada alguna de las pertenencias de la SLM ejecutante, se reclame el cumplimiento del pago de la cuota social.

\section{3) El Fallo}

La Cuarta Sala de la Corte Suprema, integrada por los Ministros señores Juan Fuentes B., Lamberto Cisternas R., Ricardo Blanco H., y los abogados integrantes seńores Ricardo Peralta V., y Arturo Prado P., en dos fallos sucesivos de fecha 2 de diciembre de 2014, rechazó los recursos de casación en el fondo acumulados (roles 5340-2013 y 5373-2013) contra las sentencias de la Corte de Apelaciones de Copiapó que desestimaron la excepción de incompetencia opuesta por los ejecutados. Ambos fallos declararon lo siguiente, en la parte que nos interesa:

"Quinto: La competencia opera, junto a la noción de jurisdicción plena del tribunal que conozca y dé solución a un determinado conflicto, como uno de los presupuestos basales del principio de rango constitucional del debido proceso y admite diversas clasificaciones (...) es por esencia divisible y emerge, según cada caso, de la aplicación de las denominadas reglas generales de la competencia -radicación, extensión, prevención, jerarquía o grado y ejecución-; de las reglas especiales de competencia -fuero, materia y cuantía-; de la competencia relativa-que mira al territorio - y de la competencia específica- vinculada al conflicto que subyace a la litis-, la que se mide directamente dentro del proceso. Sexto: Que la competencia absoluta, que ocupa estas reflexiones, surge delineada por las reglas especiales de competencia mencionadas en el 
párrafo anterior y, será de insoslayable presencia cada vez que el órgano jurisdiccional defina la admisibilidad de la cuestión que se le llame a resolver, puesto que de ello dependerá, entre otros aspectos, la validez de su actuación. Se trata, entonces, de un elemento de orden público e irrenunciable, que hace eco del mayor o menor interés insito en la contienda y concerniente, por lo tanto, al orden u organización según la cual se estructura el Poder Judicial, puesto que determina la clase y jerarquia del tribunal que habrá de conocer de un cierto asunto".

(...)

Noveno: Que, del tenor literal del precepto transcrito, forzoso resulta concluir que el artículo 146 del referido código establece la norma general en materia de competencia; a lo que se agrega que no existe norma especial que regule el juicio de inconcurrencia, ya que las normas que cita el ejecutante en apoyo de sus pretensiones, a saber, los articulos 173, 183, 189, 195 y $197 N^{\circ} 3$ del Código de Minería, se refieren a otros asuntos, los que no procede aplicar por analogía, teniendo en especial consideración que las normas que se refieren a la competencia de los tribunales son de derecho público y, como tales, solo admiten una interpretación restringida”.

El fallo fue acordado con el voto en contra del abogado integrante señor Arturo Prado P., quien fue de la opinión de acoger los recursos de casación formulados. Ello en atención a lo siguiente:

"Séptimo: (...) que de aplicarse esta norma con sentido estricto y absoluto, estaría en colisión con lo dispuesto el Artículo 174 del Código de Minería que admite la posibilidad que la sociedad pueda comprender dos o más concesiones, siempre que los socios sean unos mismos y tengan igual participación en cada una de ellas", lo cual impide fijar un domicilio social cierto con arreglo a la pura directriz que atiende al lugar donde la pertenencia se encuentra ubicada, ya que podría ser simultáneamente titular de varias concesiones ubicadas en distintos lugares, lo que impediria discernir cual el tribunal competente.

(...)

Décimo: (...) siendo la inconcurrencia un asunto minero, corresponde dar cabal aplicación a la reserva que establece la frase final del artículo 146, lo que necesariamente nos conduce a aplicar los articulos $134 y$ 138 del Código Orgánico de Tribunales en relación con los artículos 578 y 580 del Código Civil (...)".

Undécimo: (...) en el supuesto que exista mora de la sociedad legal minera en repartir y distribuir las utilidades y beneficios del ejercicio, de acuerdo a lo dispuesto en artículo 194 del Código de Minas, en relación con lo establecido en el artículo 2055 inciso segundo del Código Civil, 
lo que nos hace volver a la regla general y común que autoriza al socio a exigir y demandar a la entidad en su domicilio social efectivo, que puede no estar vinculado ni coincidir -como ocurre en la especie-con el lugar donde se encuentra ubicada la concesión minera". 